\title{
Making polymer membranes immobilized with phosphate solubilizing bacteria to produce controlled release fertilizer in combination with microorganisms
}

\author{
Linh D. P. Bui ${ }^{1,2 *}$, Hung T. Huynh ${ }^{3}$, Ha N. Nguyen ${ }^{4}$, \& Luan Q. Le ${ }^{5}$ \\ ${ }^{1}$ Department of Biology, Dong Nai University, Dong Nai, Vietnam \\ ${ }^{2}$ Department of Biotechnology, Nong Lam University, Ho Chi Minh City, Vietnam \\ ${ }^{3}$ Faculty of Agronomy, Nong Lam University, Ho Chi Minh City, Vietnam \\ ${ }^{4}$ Research Institute for Biotechnology and Environment, Nong Lam University, Ho Chi Minh City, Vietnam \\ ${ }^{5}$ Biotechnology Center of Ho Chi Minh City, Ho Chi Minh City, Vietnam
}

ARTICLE INFO
Research Paper
Received: April 04, 2018
Revised: May 28, 2018
Accepted: June 20, 2018
Keywords
Bacterial immobilization
Chitosan
Polyvinyl alcolhol
Slow release fertilizer

*Corresponding author
Bui Doan Phuong Linh
Email: plinhdl2@gmail.com

\section{ABSTRACT}

The combination of slow-release nutrients with microbial activities in a fertilizer product could increase the fertilizer's efficiency, and limit the impact of chemical hazard of fertilizer on the environment. The aim of this research was to determine the optimal parameters for adequate size of immobilized bacterial particles, mechanical properties of polyvinyl alcohol (PVA) and chitosan membranes with or without intergrating of immobilized bacterial particles to produce slow release fertilizer. The result showed that the combination of $1 \%$ sodium alginate concentration (molecular weight of $100 \mathrm{kDa}$ ) and $1 \%$ calcium chloride concentration was optimal for the preparation of immobilized microbial calcium alginate particles. The activity of phosphate solubilizing bacteria Burkholderia silvatlantica immobilized in micro calcium alginate particles, in PVA membrane, and in chitosan membrane after $72 \mathrm{~h}$ was about $84.2 \%, 82.2 \%$, and $52.9 \%$, respectively in comparison with free bacteria. Mechanical properties of PVA membrane with and without bacterial immobilized particles with modulus, elongation, and toughness were 0.122 GPa, 115.1\%, 17.65 MPa and 0.022 GPa, 220.8\%, 18.70 MPa, respectively. Mechanical properties of chitosan membrane with and without bacterial immobilized particles with modulus, elongation, and toughness were $0.6 \mathrm{GPa}, 7.6 \%, 0.66 \mathrm{MPa}$ and $0.842 \mathrm{GPa}, 32.4 \%, 3.52 \mathrm{MPa}$, respectively.

Cited as: Bui, L. D. P., Huynh, H. T., Nguyen, H. N., \& Le, L. Q. (2019). Making polymer membranes immobilized with phosphate solubilizing bacteria to produce controlled release fertilizer in combination with microorganisms. The Journal of Agriculture and Development 18(2), 105-111. 


\title{
Bước đầu nghiên cứu tạo màng Polymer cố định vi khuẩn giải lân định hướng tạo phân bón tan chậm kết hợp vi sinh vật
}

\author{
Bùi Đoàn Phượng Linh ${ }^{1,2 *}$, Huỳnh Thanh Hùng ${ }^{3}$, Nguyễn Ngọc Hà $^{4}$ \& Lê Quang Luân ${ }^{5}$ \\ ${ }^{1}$ Bộ Môn Sinh, Trường Đại Học Đồng Nai, Đồng Nai \\ ${ }^{2}$ Bộ Môn Công nghệ Sinh học, Trường Đại Học Nông Lâm, Tp. Hồ Chí Minh, Tp. Hồ Chí Minh \\ ${ }^{3}$ Khoa Nông Học, Trường Đại Học Nông Lâm TP. Hồ Chí Minh, TP. Hồ Chí Minh \\ ${ }^{4}$ Viện Nghiên Cứu Công Nghệ Sinh Học và Môi Trường, Trường Đại Học Nông Lâm, TP. Hồ Chí Minh \\ ${ }^{5}$ Trung Tâm Công Nghệ Sinh Học TP. Hồ Chí Minh, TP. Hồ Chí Minh
}

\section{THÔNG TIN BÀI BÁO \\ Bài báo khoa học \\ Ngày nhận: 04/04/2018 \\ Ngày chỉnh sửa: 28/05/2018 \\ Ngày chấp nhận: 20/06/2018}

\section{Từ khóa \\ Chitosan \\ Cố định vi khuẩn \\ Phân bón tan chậm \\ Polyvinyl alcolhol}

\section{*Tác giả liên hệ}

Bùi Đoàn Phượng Linh

Email: plinhdl2@gmail.com

\section{TÓM TẮT}

Sự kết hợp giữa khả năng phóng thích chất dinh dưỡng chậm với hoạt động của vi sinh vật trong một sản phẩm phân bón là một giải pháp góp phần tăng hiệu suất sử dụng phân bón và hạn chế tác động của phân bón tới môi trường. Nghiên cứu nhằm xác định các thông số tối ưu cho quy trình tạo vi hạt cố định vi khuẩn có kích thước thích hợp và các tính chất cơ học của màng polyvinyl alcohol (PVA) và chitosan có chứa và không chứa các vi hạt cố định vi khuẩn phân giải lân nhằm tạo màng polymer trong sản xuất phân bón tan chậm kết hợp vi sinh vật. Kết quả cho thây natri alginate có khối lượng phân tử $100 \mathrm{kDa}$ ở nồng độ $1 \%$ và calcium clorua $1 \%$ là thích hợp nhất để tạo vi hạt cố định vi khuẩn. Hoạt tính phân giải lân của vi khuẩn cố định trong vi hạt calcium alginate, cố định trong màng PVA và màng chitosan cũng được khảo sát với kết quả sau 72 giờ lần lượt là $84,2 \%, 82,2 \%$ và $52,9 \%$ so với vi khuẩn tự do. Đặc tính cơ lý của màng PVA có chứa vi hạt cố định vi khuẩn và không chứa vi hạt cố định vi khuẩn với các thông số modulus, độ giãn dài và độ bền lần lượt là $0,122 \mathrm{GPa}, 115,1 \%, 17,65 \mathrm{MPa}$ và $0,022 \mathrm{GPa}, 220,8 \%, 18,70 \mathrm{MPa}$. Đặc tính cơ lý của màng chitosan có chứa vi hạt cố định vi khuẩn và không chứa vi hạt cố định vi khuẩn có thông số modulus, độ giãn dài và độ bền lần lượt là $0,6 \mathrm{MPa}, 7,6 \%, 0,66 \mathrm{MPa}$ và $0,842 \mathrm{GPa}, 32,4 \%, 3,52 \mathrm{MPa}$.

\section{1. Đắt Vấn Đề}

Hiệu suất sử dụng của nhiều loại phân bón vô cơ hiện nay chưa cao do quá trình hòa tan, bay hơi và rửa trôi của phân diễn ra nhanh, cây trồng không kịp hấp thu, dẫn tới lãng phí, gây ô nhiễm môi trường và ảnh hưởng tới hệ vi sinh vật có ích trong đất (Naz \& Sulaiman, 2016). Sử dụng phân bón tan chậm với màng bao tạo bởi các polymer là một trong các giải pháp vẫn đảm bảo năng suất cây trồng nhưng lại góp phần hạn chế thất thoát dinh dưỡng, giảm thiểu tác động của phân bón tới môi trường (Shaviv, 2001; Trenkel, 2010; Azeem \& ctv., 2014). Mặt khác, góp phần nâng cao năng suất cây trồng trong sản xuất nông nghiệp còn có sự tham gia tích cực của các vi sinh vật có ích trong đất. Một sản phẩm phân bón trong đó có sự kết hợp giữa phóng thích chất dinh dưỡng chậm và hoạt động của vi sinh vật sẽ giúp nâng cao hiệu suất sử dụng phân bón và bổ sung nguồn vi sinh vật có ích cho đất.

Phương pháp cố định tế bào là một kỹ thuật hiện nay đang được nghiên cứu và sử dụng nhiều trong lĩnh vực lên men sản xuất các sản phẩm trao đổi chất và xử lý môi trường. Việc sử dụng tế bào cố định có nhiều ưu điểm vượt trội hơn so với tế bào tự do như: giúp kéo dài và ổn định hoạt động của các enzyme do vi sinh vật tiết ra, hỗ trợ giúp bảo vệ tế bào chống lại tác động bất lợi của các tác nhân lý hóa như pH, nhiệt độ, dung môi hoặc thậm chí là cả kim loại nặng (Kourkoutas \& 
ctv., 2004). Dựa trên ưu điểm này, nếu vi khuẩn được cố định trong một vi hạt bằng phương pháp cố định tế bào sẽ giúp hạn chế tác động của phân bón tới vi sinh vật khi kết hợp vi sinh vật với phân hóa học.

Hướng tới mục tiêu kết hợp giữa tính năng ưu việt của phân bón tan chậm với tiềm năng sinh học to lớn của vi sinh vật để tạo ra một sản phẩm phân bón vừa có lợi cho sản xuất nông nghiệp vừa thân thiện với môi trường. Nghiên cứu này được thực hiện nhằm xác định các thông số tối ưu cho quy trình tạo vi hạt cố định vi khuẩn có kích thước thích hợp, bổ sung vào màng bao phân bón và các đặc trưng cơ lý của màng tạo bởi hai loại polymer là polyvinyl alcohol (PVA) và chitosan chứa và không chứa các vi hạt cố định vi khuẩn phân giải lân khó tan giúp định hướng tạo phân bón tan chậm với vỏ bọc là các polymer có kết hợp vi sinh vật để tăng hiệu quả sử dụng phân bón và bổ sung nguồn vi sinh vật có ích cho đất, đặc biệt là vi khuẩn chuyển hóa lân khó tan.

\section{Vật Liệu và Phương Pháp Nghiên Cứu}

\subsection{Vật liệu}

Chủng vi khuẩn phân giải lân Burkholderia silvatlantica do Bộ môn Sinh học Trường Đại học Đồng Nai cung cấp. B. silvatlantica là vi khuẩn gram âm, hình que, di chuyển bằng roi, sinh trưởng tốt trong điều hiếu khí ở nhiệt độ $29^{\circ} \mathrm{C}$, bất hoạt ở $42^{\circ} \mathrm{C}$, sinh sản bằng hình thức phân đôi tế bào (Perin \& ctv., 2006).

Hóa chất: PVA 217, chitosan nông nghiệp, ethanol, calcium clorua $\left(\mathrm{CaCl}_{2}\right)$ và natri alginate ở các khối lượng phân tử 903 kDa, 500 kDa, 200 $\mathrm{kDa}$ và $100 \mathrm{kDa}$.

\subsection{Phương pháp khảo sát ảnh hưởng của} nồng độ natri alginate đến kích thước hạt

Chuẩn bị dung dịch natri alginate có khối lượng phân tử $903 \mathrm{kDa}$ ở các nồng độ $1 \%, 2 \%, 3 \%$ và dung dịch $\mathrm{CaCl}_{2}$ ở nồng độ $2 \%$. Cho từ từ dung dịch natri alginate vào dung dịch $\mathrm{CaCl}_{2}$ theo tỉ lệ 1:5, kết hợp dùng máy đồng hóa (Homogenizer, Bibby Scientific, Anh) khuấy đảo tạo dung dịch đồng nhất và ổn định hạt trong 30 phút. Lọc và rửa hạt thu được với nước cất. Tiến hành đo kích thước các hạt tạo được bằng máy Lazer diffraction particle size analyzer LS 13 320, Beckman coulter, Mỹ. Chọn nồng độ natri alginate cho kích thước hạt nhỏ nhất để thực hiện các thí nghiệm tiếp theo.

\subsection{Phương pháp khảo sát ảnh hưởng của nồng độ $\mathrm{CaCl}_{2}$ đến kích thước hạt}

Chuẩn bị dung dịch natri alginate có khối lượng phân tử $903 \mathrm{kDa}$ ở nồng độ dung dịch được đề xuất ở kết quả khảo sát ảnh hưởng của nồng độ natri alginate dến kích thước hạt và dung dịch $\mathrm{CaCl}_{2}$ ở nồng độ $1 \%, 3 \%, 5 \%$. Cho từ từ dung dịch natri alginate vào dung dịch $\mathrm{CaCl}_{2}$ theo tỉ lệ (1:5), kết hợp dùng máy dồng hóa (Homogenizer, Bibby Scientific, Anh) khuấy đảo tạo dung dịch đồng nhất và ổn định hạt trong 30 phút. Lọc và rửa hạt thu được với nước cất. Tiến hành đo kích thước các hạt tạo được bằng máy Lazer diffraction particle size analyzer LS 13 320, Beckman coulter, Mỹ. Chọn nồng độ $\mathrm{CaCl}_{2}$ cho kích thước hạt nhỏ nhất để thực hiện các thí nghiệm tiếp theo.

\subsection{Phương pháp khảo sát ảnh hưởng của khối lượng phân tử natri alginate đến kích thước hạt}

Chuẩn bị các dung dịch natri alginate có khối lượng phân tử 100 kDa, 200 kDa, 500 kDa, 903 $\mathrm{kDa}$ ở nồng độ được đề xuất ở thí nghiệm khảo sát ảnh hưởng của nồng độ natri alginate tới kích thước hạt và dung dịch $\mathrm{CaCl}_{2}$ ở nồng độ được đề xuất ở thí nghiệm khảo sát ảnh hưởng của nồng độ $\mathrm{CaCl}_{2}$ đến kích thước hạt. Cho từ từ dung dịch natri alginate vào dung dịch $\mathrm{CaCl}_{2}$ theo tî̉ lệ 1:5, kết hợp dùng máy đồng hóa (Homogenizer, Bibby Scientific, Anh) khuấy đảo tạo dung dịch đồng nhất và ổn định hạt trong 30 phút. Lọc và rửa hạt thu được với nước cất. Tiến hành đo kích thước các hạt tạo được bằng máy Lazer diffraction particle size analyzer LS 13 320, Beckman coulter, Mỹ. Chọn khối lượng phân tử natri alginate cho kích thước hạt nhỏ nhất để thực hiện các thí nghiệm tiếp theo.

\subsection{Phương pháp cố định tế bào vi khuẩn và tạo màng bao polymer chứa vi hạt cố định vi khuẩn}

Vi khuẩn phân giải lân B.silvatlantica được cố định bằng phương pháp nhốt tạo gel với chất mang là natri alginate kết hợp với $\mathrm{CaCl}_{2}$ với khối lượng phân tử và nồng độ phần trăm thích hợp được đề xuất ở kết quả của các thí nghiệm trên, thanh trùng, trộn sinh khối vi khuẩn sao cho được 
mật độ $10^{9}$ tế bào $/ \mathrm{mL}$. Sau đó, các vi hạt calcium alginate đã cố định vi khuẩn được phân tán vào dung dịch PVA 4\%, chitosan $4 \%$ và tạo hỗn hợp đồng nhất. Hỗn hợp được đổ khuôn tạo màng và để khô ở $4^{0} \mathrm{C}$ trong 48 giờ.

\subsection{Phương pháp khảo sát hoạt tính của vi khuẩn Burkholderia silvatlantica}

Hoạt tính phân giải lân của vi khuẩn B. silvatlantica tự do, vi khuẩn được cố định trong các vi hạt calcium alginate và trong màng $\mathrm{PVA}$ và chitosan được xác định bằng phương pháp đo kích thước vòng phân giải trên môi trường Pikovskaya, là môi trường kiểm tra vi sinh vật phân giải các hợp chất phospho vô cơ khó tan theo TCVN 6167:1996 (Bảng 1) trong thời gian nuôi ủ 24 giờ, 48 giờ và 72 giờ. Mỗi đĩa môi trường được tạo giếng có kích thước $9 \mathrm{~mm}$. Hoạt tính vòng giải được đánh giá bằng hiệu số $\mathrm{D}-\mathrm{d}(\mathrm{mm})$, trong đó $\mathrm{D}$ là đường kính vòng phân giải $(\mathrm{mm}), \mathrm{d}$ là đường kính giếng môi trường (mm).

Bảng 1. Thành phần và nồng độ của môi trường Pikovskaya kiểm tra vi sinh vật phân giải các hợp chất phospho vô cơ khó tan

\begin{tabular}{lc}
\hline Thành phần & Nồng độ $(\mathrm{g} / \mathrm{L})$ \\
\hline Glucose & 10,0 \\
$\mathrm{Ca}_{3}\left(\mathrm{PO}_{4}\right)_{2}$ & 5,0 \\
$\left(\mathrm{NH}_{4}\right)_{2} \mathrm{SO}_{4}$ & 0,5 \\
$\mathrm{KCl}$ & 0,2 \\
$\mathrm{MgSO}_{4} \cdot 7 \mathrm{H}_{2} \mathrm{O}$ & 0,1 \\
$\mathrm{MnSO}_{4}$ & Vết \\
$\mathrm{FeSO}_{4}$ & Vết \\
$\mathrm{Nấm} \mathrm{men}_{\text {Agar }}$ & 0,5 \\
Nước cất & 20,0 \\
pH & 1 lít \\
\hline
\end{tabular}

Khảo sát hoạt tính vi khuẩn: vi khuẩn $B$. silvatlantica tự do được tăng sinh khối trong 50 $\mathrm{mL}$ môi trường $\mathrm{LB}$ (cho $10 \mathrm{~g} \mathrm{NaCl}, 10 \mathrm{~g}$ pepton, $5 \mathrm{~g}$ nấm men, trong $1000 \mathrm{~mL}$ nước cất, $\mathrm{pH}$ $6,7-7)$ ở $30^{0} \mathrm{C}$ trong 48 giờ. Ly tâm $4000 \mathrm{rpm}$ trong 15 phút, thu sinh khối, tái huyền phù trong $10 \mathrm{~mL}$ nước cất vô trùng. Đo mật độ quang của dung dịch huyền phù ở bước sóng 600 nm. Hút 30 $\mu \mathrm{L}$ dung dịch huyền phù vào giếng trên đĩa môi trường đã chuẩn bị ở trên. Ủ ở $30^{0} \mathrm{C}$, tiến hành đo kích thước vòng phân giải sau 24 giờ, 48 giờ và 72 giờ.

\subsection{Phương pháp khảo sát đặc tính cơ lý của màng PVA và Chitosan}

Các giá trị modulus, độ giãn dài (Strain At Break) và độ dẻo dai (Toughness) của màng PVA, chitosan chứa và không chứa các vi hạt calcium alginate được đo đạc trên máy kiểm tra tính chất cơ học của vật liệu nano (Nanomechanical Characterization Machine U9815A UTM 150, Keysight Technology, Mỹ). Mẫu được chuẩn bị và kiểm tra tính chất cơ học theo tiêu chuẩn ISO 527 (1993) với các thông số được thể hiện trong Bảng 2.

Các thí nghiệm được bố trí ngẫu nhiên theo kiểu CRD một nhân tố với các nghiệm thức khác nhau, mỗi nghiệm thức lặp lại 3 lần. Số liệu được xử lý bằng phần mềm Microsoft Office Excel 2007 và MSTATC 1.2.

\section{Kết Quả và Thảo Luận}

\section{1. Ảnh hưởng của nồng độ natri alginate đến kích thước hạt}

Nồng độ natri alginate có ảnh hưởng đến kích thước vi hạt calcium alginate tạo ra trong quá trình tạo gel với $\mathrm{CaCl}_{2}$. Kết quả thể hiện trong Bảng 3 cho thấy khi giảm nồng độ natri alginate thì kích thước vi hạt tạo được cũng giảm theo. Cụ thể tại nồng độ natri alginate là $3 \%$ kích thước vi hạt tạo được là lớn nhất $(457,5 \mu \mathrm{M})$ và khác biệt có ý nghĩa thống kê so với nồng độ natri alginat $2 \%$ và $1 \%$, trong khi đó ở nồng độ natri alginate $1 \%$ kích thước vi hạt được tạo ra là nhỏ nhất $(262,3 \mu \mathrm{M})$. Điều này có thể là do khi nồng độ natri alginate cao thì độ nhớt của dung dịch cũng cao, dẫn đến khả năng phân tán của natri alginate trong dung dịch $\mathrm{CaCl}_{2}$ giảm, số lượng phân tử natri alginate tham gia liên kết tạo gel cũng nhiều hơn so với dung dịch ở nồng độ thấp nên dẫn đến kích thước hạt tạo ra lớn hơn so với khi giảm nồng độ natri alginate. Nồng độ natri alginat $1 \%$ sẽ được chọn cho các khảo sát tiếp theo.

\section{2. Ảnh hưởng của nồng độ calcium clorua đến kích thước hạt}

Nồng độ $\mathrm{CaCl}_{2}$ cũng là một yếu tố có ảnh hưởng đến kích thước vi hạt calcium alginate. Kết quả Bảng 4 cho thấy khi giảm nồng độ $\mathrm{CaCl}_{2}$ thì kích thước hạt tạo được cũng giảm theo. Cụ thể, tại nồng độ $\mathrm{CaCl}_{2} 5 \%$ kích thước vi hạt tạo được 
Bảng 2. Các thông số của màng PVA và chitosan

\begin{tabular}{ccccc}
\hline \multicolumn{2}{c}{ Các thông số của màng } & Chiều dài $(\mathrm{mm})$ & Chiều rộng $(\mathrm{mm})$ & Độ dày $(\mathrm{mm})$ \\
\hline \multirow{2}{*}{ Màng chitosan } & Không hạt & $45,5 \pm 0,1$ & $0,43 \pm 0,060$ & $0,039 \pm 0,001$ \\
& Có hạt & $45,5 \pm 0,1$ & $0,62 \pm 0,030$ & $0,061 \pm 0,001$ \\
\hline \multirow{2}{*}{ Màng PVA } & Không hạt & $41,6 \pm 0,6$ & $0,41 \pm 0,013$ & $0,032 \pm 0,001$ \\
& Có hạt & $31,1 \pm 2,0$ & $0,35 \pm 0,003$ & $0,023 \pm 0,001$ \\
\hline
\end{tabular}

Bảng 3. Kích thước trung bình của các vi hạt calcium alginate ở các nồng độ natri alginate khác nhau

\begin{tabular}{cc}
\hline $\begin{array}{c}\text { Nồng độ } \\
\text { natri alginate } \\
(\%)\end{array}$ & $\begin{array}{c}\text { Kích thước hạt } \\
\text { trung bình } \pm \mathrm{SD}\end{array}$ \\
\hline 1 & $262,93^{\mathrm{a}} \pm 11,55$ \\
2 & $297,80^{\mathrm{a}} \pm 1,31$ \\
3 & $475,50^{\mathrm{b}} \pm 18,22$ \\
\hline
\end{tabular}

a-b Trong cùng một cột, các giá trị trung bình có kí tự theo sau khác nhau thể hiện sự khác biệt có ý nghĩa về mặt thống kê $(P<0,05)$.

là lớn nhất, còn ở nồng độ $1 \%$ kích thước vi hạt tạo ra là nhỏ nhất trong 3 nghiệm thức. Do vậy, dung dịch calcium clorua nồng độ 1\% được chọn cho các khảo sát tiếp theo.

Bảng 4. Kích thước trung bình của các hạt calcium alginate ở các nồng độ calcium clorua khác nhau

\begin{tabular}{cc}
\hline $\begin{array}{c}\text { Nồng độ } \mathrm{CaCl}_{2} \\
(\%)\end{array}$ & $\begin{array}{c}\text { Kích thước hạt } \\
\text { trung bình } \pm \mathrm{SD} \\
(\mu \mathrm{M})\end{array}$ \\
\hline 1 & $257,33^{\mathrm{a}} \pm 9,53$ \\
3 & $309,50^{\mathrm{ab}} \pm 15,74$ \\
5 & $341,73^{\mathrm{b}} \pm 22,91$ \\
\hline
\end{tabular}

a-b Trong cùng một cột, các giá trị trung bình có kí tự theo
sau khác nhau thể hiện sự khác biệt có ý nghĩa về mặt thống kê $(P<0,05)$.

\section{3. Ảnh hưởng của khối lượng phân tử natri alginate đến kích thước hạt}

Khi đồng nhất các yếu tố ảnh hưởng đến kích thước hạt như nồng độ natri alginate, nồng độ $\mathrm{CaCl}_{2}$ và tốc độ khuấy, kết quả cho thấy khối lượng phân tử natri alginate cũng ảnh hưởng tới kích thước hạt được tạo ra. Theo Bảng 5 , khối lượng phân tử natri alginate tỉ lệ thuận với kích thước các vi hạt calium alginate. Tại nghiệm thức với natri alginate có khối lượng phân tử $903 \mathrm{kDa}$, kích thước vi hạt tạo được là lớn nhất $(250,93)$, khác biệt rất có ý nghĩa thống kê so với các nghiệm thức còn lại $(P<0,05)$. Tại nghiệm thức natri alginate có khối lượng phân tử 100 kDa, kích thước vi hạt tạo ra là nhỏ nhất $(68,10 \mu \mathrm{M})$. Điều này có thể là do độ dài ngắn của mạch natri alginate có ảnh hưởng quyết định đến độ nhớt của dung dịch khi hòa tan natri alginate vào nước. Natri alginate ở khối lượng phân tử càng thấp thì chuỗi polymer của natri alginate càng ngắn. Natri alginate có khối lượng phân tử càng lớn, mạch polymer sẽ càng dài, độ nhớt dung dịch càng tăng, mà độ nhớt dung dịch tăng dẫn đến kích thước vi hạt calcium alginate sẽ lớn. Natri alginate có khối lượng phân tử $100 \mathrm{kDa}$ sẽ được chọn để tiến hành thí nghiệm cố định vi khuẩn.

Bảng 5. Kích thước trung bình của các vi hạt calcium alginate được tạo ra với natri alginate có khối lượng phân tử khác nhau

\begin{tabular}{cc}
\hline $\begin{array}{c}\text { Khối lượng phân tử } \\
\text { natri alginate }(\mathrm{kDa})\end{array}$ & $\begin{array}{c}\text { Kích thước hạt } \\
\text { trung bình } \pm \mathrm{SD} \\
(\mu \mathrm{M})\end{array}$ \\
\hline 903 & $250,93^{\mathrm{a}} \pm 4,19$ \\
500 & $145,66^{\mathrm{b}} \pm 7,61$ \\
200 & $85,55^{\mathrm{c}} \pm 4,03$ \\
100 & $68,10^{\mathrm{c}} \pm 5,25$ \\
\hline
\end{tabular}

a-c Trong cùng môt côt, các giá tri trung bình có kí tự theo sau khác nhau thể hiện sự khác biệt có ý nghĩa về mặt thống kê $(P<0,05)$.

3.4. Độ bền cơ lý của màng PVA, chitosan chứa và không chứa các vi hạt cố định vi khuẩn

Độ bền cơ lý của màng PVA và chitosan được xác định qua các thông số modulus. Modulus là một tính chất cơ học đặc trưng cho vật liệu rắn đàn hồi tuyến tính. Nó biểu thị lực cần để kéo giãn một vật, độ giãn dài và độ bền. Modulus càng thấp thì màng càng dễ bị kéo giãn.

Kết quả thí nghiệm cũng cho thấy sự hiện diện của các vi hạt calcium alginate trong cấu trúc màng PVA và chitosan đã ảnh hưởng đến tính đàn hồi của màng. Giá trị Modolus của màng PVA không chứa các vi hạt và chứa vi hạt lần lượt là $0,022 \mathrm{GPa}$ và $0,122 \mathrm{GPa}$, còn của màng 
Bảng 6. Đặc trưng cơ lý của màng PVA và chitosan chứa và không chứa các vi hạt cố định vi khuẩn

\begin{tabular}{ccccc}
\hline \multirow{2}{*}{ Đặc trưng cơ lý của màng } & $\begin{array}{c}\text { Modulus } \pm \text { SD } \\
(\mathrm{GPa})\end{array}$ & $\begin{array}{c}\text { Độ giãn dài } \pm \mathrm{SD} \\
(\%)\end{array}$ & $\begin{array}{c}\text { Độ bền } \pm \mathrm{SD} \\
(\mathrm{MPa})\end{array}$ \\
\hline \multirow{2}{*}{ Màng PVA } & Không hạt & $0,022 \pm 0,003$ & $220,8 \pm 8,60$ & $18,70 \pm 1,16$ \\
& Có hạt & $0,122 \pm 0,023$ & $115,1 \pm 7,10$ & $17,65 \pm 0,67$ \\
\hline \multirow{2}{*}{ Màng chitosan } & Không hạt & $0,842 \pm 0,107$ & $32,4 \pm 0,03$ & $3,52 \pm 0,29$ \\
& Có hạt & $0,600 \pm 0,039$ & $7,6 \pm 0,01$ & $0,66 \pm 0,01$ \\
\hline
\end{tabular}

chitosan lần lượt là $0,842 \mathrm{GPa}$ và $0,600 \mathrm{GPa}$. Mặt khác nghiên cứu cũng chỉ ra các vi hạt không chỉ ảnh hưởng đến tính đàn hồi mà còn ảnh hưởng đến độ giãn dài, độ bền của màng PVA và chitosan. Giá trị độ giãn dài của màng PVA và chitosan không chứa vi hạt calcium alginate (220,8\% và $32,4 \%$ ) cao hơn so với màng $\mathrm{PVA}$ và chitosan có chứa các vi hạt calcium alginate $(115,1 \%$ và $7,6 \%)$. Giá trị độ bền của màng PVA và chitosan không chứa các vi hạt là $18,70 \mathrm{MPa}, 3,52 \mathrm{MPa}$, trong khi đó độ bền của màng $\mathrm{PVA}$ và chitosan có chứa các vi hạt là $17,65 \mathrm{MPa}$ và $0,66 \mathrm{MPa}$. Mặt khác, so sánh độ bền cơ lý của màng PVA và chitosan với nhau cho thấy Modolus của màng PVA thấp hơn so với màng chitosan, trong khi đó độ giãn dài và độ bền của màng PVA lại cao hơn của màng chitosan ở cả hai trường hợp có và không có vi hạt cố định vi khuẩn (Bảng 6). Modulus càng thấp thì màng càng dễ bị kéo dãn, nhưng không đồng nghĩa với modulus thấp hơn thì khả năng đàn hồi của vật liệu sẽ tốt hơn, mà còn phụ thuộc vào cấu trúc cũng như thành phần của vật liệu tạo màng. Các thông số về độ bền cơ lý của màng PVA, chitosan cho thấy PVA và chitosan là một trong các polymer có khả năng được lựa chọn làm màng bao phân tan chậm, kết quả này cũng phù hợp với nghiên cứu của Nguyen (2013) và Lubkowski (2014).

3.5. Hoạt tính phân giải lân của vi khuẩn Burkholderia silvatlantica trong các vi hạt calcium alginate, trên màng $\mathrm{PVA}$ và chitosan

Hoạt tính phân giải lân vô cơ khó tan của vi khuẩn $B$. silvatlantica thể hiện ở kích thước vòng phân giải bao quanh vi khuẩn tự do, các vi hạt calcium alginate cố định vi khuẩn, màng $\mathrm{PVA}$ và màng chitosan có chứa vi khuẩn được cố định trong các vi hạt như quan sát thấy ở Hình 1 .

Kết quả được thể hiện ở Bảng 7 cho thấy ở thời điểm 24 giờ sau khi ủ thì màng PVA chứa vi khuẩn cố định, màng chitosan chứa vi khuẩn

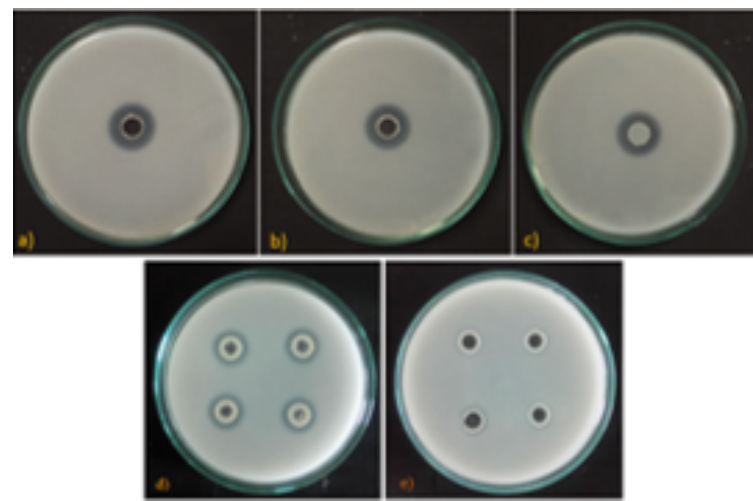

Hình 1. Vòng phân giải hợp chất phospho vô cơ khó tan của vi khuẩn $B$. silvatlantica ở thời điểm 48 giờ (a. Vi khuẩn tự do, b. Vi khuẩn được cố định trong calium alginat, c. Màng PVA chứa vi hạt cố định vi khuẩn, d. Màng chitosan chứa hạt vi khuẩn cố định và e. Màng chitosan chứa vi khuẩn tự do).

tự do và vi khuẩn cố định đều không thấy xuất hiện vòng phân giải. Ở thời điểm 48 giờ, 72 giờ tất cả các đĩa nuôi cấy đều xuất hiện vòng phân giải trừ màng chitosan chứa vi khuẩn tự do. So sánh các kết quả cho thấy vi khuẩn tự do khi được nuôi cấy trong môi trường kiểm tra vi sinh vật phân giải các hợp chất phospho vô cơ khó tan phát triển mạnh hơn so với vi khuẩn được cố định trong các vi hạt calcium alginate và vi khuẩn được cố định trong các vi hạt calcium alghinate trên màng PVA và màng chitosan. Điều này có thể giải thích là do được bọc trong vỏ calcium alginate hoặc vi khuẩn được cố định trong các vi hạt phân tán trong màng PVA, màng chitosan nên sự sinh trưởng và phát triển của vi khuẩn sẽ chậm hơn so với vi khuẩn tự do. Vi khuẩn cần có thời gian tiết ra enzyme hoặc được phóng thích ra bên ngoài vi hạt calcium alginate, từ đó sẽ phân giải được các hợp chất phospho trong môi trường dẫn tới khả năng phân giải sẽ chậm.

Dựa trên kích thước vòng phân giải phospho khó tan sau 72 giờ của vi khuẩn cố định trong vi 
Bảng 7. Kích thước trung bình của vòng phân giải hợp chất phospho vô cơ khó tan của vi khuẩn Burkholderia silvatlantica theo thời gian

\begin{tabular}{cccccc}
\hline \multirow{2}{*}{$\begin{array}{c}\text { Thời gian } \\
\text { ủ (giờ) }\end{array}$} & $\begin{array}{c}\text { Vi khuẩn } \\
\text { tự do }\end{array}$ & $\begin{array}{c}\text { Vi khuẩn } \\
\text { cốn định }\end{array}$ & $\begin{array}{c}\text { Màng PVA chứa } \\
\text { vi khuẩn } \\
\text { cồ định }\end{array}$ & $\begin{array}{c}\text { Chứa vi khuẩn } \\
\text { tự do }\end{array}$ & $\begin{array}{c}\text { Chứa vi khuẩn } \\
\text { cố định }\end{array}$ \\
\hline 24 & $5,01 \pm 0,07$ & $4,82 \pm 0,03$ & 0,00 & 0,00 & 0,00 \\
48 & $8,51 \pm 0,18$ & $7,64 \pm 0,04$ & $6,63 \pm 0,26$ & 0,00 & $1,42 \pm 0,12$ \\
72 & $9,87 \pm 0,08$ & $8,31 \pm 0,18$ & $8,11 \pm 0,27$ & 0,00 & $5,22 \pm 0,10$ \\
\hline
\end{tabular}

hạt calcium alginate $(8,31 \mathrm{~mm})$, vi khuẩn được cố định trong vi hạt calcium alginate trên màng PVA $(8,11 \mathrm{~mm})$ và vi khuẩn tự do $(9,87 \mathrm{~mm})$ cho thấy hoạt tính phân giải lân của vi khuẩn cố định trong vi hạt calcium alginate, vi khuẩn được cố định trong vi hạt calcium alginate trên màng PVA đạt $84,2 \%, 82,2 \%$ so với vi khuẩn tự do. Đối với màng chitosan chứa vi khuẩn tự do sau 72 giờ hoàn toàn không có hoạt tính phân giải lân vô cơ khó tan, điều này có thể được giải thích là do khả năng kháng khuẩn tự nhiên của chitosan nên vi khuẩn không thể phát triển được. Nhưng đối với màng chitosan chứa vi hạt cố định vi khuẩn với kích thước vòng phân giải phospho là $5,22 \mathrm{~mm}$ cho thấy hoạt tính phân giải phospho khó tan đạt $52,9 \%$ so với vi khuẩn tự do. Như vậy cacilum alginate đã phần nào giúp bảo vệ vi khuẩn khỏi khả năng kháng khuẩn của chitosan. Qua đây cho thấy, cố định vi khuẩn trong vi hạt giúp bảo vệ vi khuẩn tránh tác động bất lợi của môi trường bên ngoài như trong nghiên cứu của Kourkoutas \& ctv. (2004).

\section{Kết Luận}

Nồng độ $1 \%$ của natri alginate có khối lượng phân tử $100 \mathrm{kDa}$ và calcium clorua $1 \%$ là thông số tối ưu cho quá trình tạo ra vi hạt calcium alginate có kích thước nhỏ nhất, là kích thước tạo thuận lợi cho việc cố định vi khuẩn vào màng bao polymer dùng để tạo màng cho phân tan chậm kết hợp vi sinh vật.

Các thông số về khả năng đàn hồi, độ dãn dài và độ bền của PVA và chitosan cho thấy cả hai vật liệu PVA và chitosan đều có thể được sử dụng làm vật liệu tạo màng. Tuy nhiên, sự hiện diện của vi hạt cố định vi khuẩn bằng calcium alginate trong cấu trúc màng PVA và chitosan là có ảnh hưởng đến tính chất cơ học của màng.

Kết quả nghiên cứu bước đầu chỉ ra rằng phương pháp tạo vi hạt cố định vi khuẩn bằng phương pháp nhốt sử dụng calcium alginate vẫn đảm bảo vi khuẩn còn hoạt tính và có thể góp phần giúp bảo vệ vi khuẩn trước tác động của điều kiện bất lợi bên ngoài. Điều này có thể là một phương cách giúp tăng khả năng sống sót của vi sinh vật khi kết hợp với phân bón hóa học cho mục tiêu tạo phân bón tan chậm kết hợp vi sinh vật.

\section{Tài Liệu Tham Khảo (References)}

Azeem, B., KuShaari, K., Man, Z. B., Basit, A., \& Thanh, T. H. (2014). Review on materials \& methods to produce controlled release coated urea fertilizer. Journal of Controlled Release 181, 11-21.

Kourkoutas, Y., Bekatorou, A., Banat, I. M., Marchant, R., \& Koutinas, A. A. (2004). Immobilization technologies and support materials suitable in alcohol beverages production: a review. Food Microbiology 21(4), 377-397.

Lubkowski, K. (2014). Coating fertilizer granules with biodegradable materials for controlled fertilizer release. Environmental Engineering \& Management Journal (EEMJ) 13(10), 2573-2581.

Naz M. Y., \& Sulaiman S. A. (2016). Slow release coating remedy for nitrogen loss from conventional urea: a review. Journal of Controlled Release 225, 109-120.

Nguyen, T. T. T. (2013). Research on synthesis of biodegradable polymers based on polyvinyl alcohol and natural polysaccharides (Unpublished doctoral dissertation). Vietnam Academy of Science and Technology, Ha Noi, Vietnam.

Perin, L., Martinez-Aguilar, L., Paredes-Valdez, G., Baldani, J. I., Estrada-De Los Santos, P., Reis, V. M., \& Caballero-Mellado, J. (2006). Burkholderia silvatlantica sp. nov., a diazotrophic bacterium associated with sugar cane and maize. International Journal of Systematic and Evolutionary Microbiology 56(8), 1931-1937.

Shaviv, A. (2001). Advances in controlled-release fertilizers. Advances in agronomy 71, 1-49.

Trenkel, M. E. (2010). Slow-and controlled-release and stabilized fertilizers: An option for enhancing nutrient use efficiency in Agriculture. Paris, France: IFA. International Fertilizer Industry Association. 